\title{
Fatal metformin overdose: case report and postmortem biochemistry contribution
}

\author{
Alessandro Bonsignore • Fulvia Pozzi • Giulio Fraternali Orcioni • \\ Francesco Ventura • Cristian Palmiere
}

Received: 10 July 2013 / Accepted: 10 October 2013 / Published online: 8 November 2013

(C) Springer-Verlag Berlin Heidelberg 2013

\begin{abstract}
Metformin is an oral antihyperglycemic agent used in the management of type 2 diabetes mellitus. Lactic acidosis from metformin overdose is a rare complication of metformin therapy and occurs infrequently with therapeutic use. Fatal cases, both accidental and intentional, are extremely rare in clinical practice. Metformin is eliminated by the kidneys, and impaired renal function can result in an increased plasma concentration of the drug. In this report, we describe an autopsy case involving a 70-year-old woman suffering from diabetes mellitus and impaired renal function who received metformin treatment. Metformin concentrations in the peripheral blood collected during hospitalization and femoral blood collected during autopsy were 42 and $47.3 \mu \mathrm{g} / \mathrm{ml}$, respectively. Lactic acidosis $(29.10 \mathrm{mmol} / \mathrm{l})$ was objectified during hospitalization. Furthermore, postmortem biochemistry allowed ketoacidosis to be diagnosed (blood $\beta$-hydroxybutyrate, $10,500 \mu \mathrm{mol} / \mathrm{l})$. Death was attributed to lactic acidosis due to metformin intoxication. Increased plasma concentrations of the drug were attributed to severely impaired renal function. The case emphasizes the usefulness of performing exhaustive toxicology and postmortem biochemistry towards the more complete understanding of the pathophysiological mechanisms that may be involved in the death process.
\end{abstract}

A. Bonsignore $\cdot F$. Ventura

Department of Legal Medicine, University of Genova, Genoa, Italy

F. Pozzi

Department of Public Health, Neurosciences, Experimental and

Forensic Medicine, University of Pavia, Pavia, Italy

G. Fraternali Orcioni

Department of Pathology, Anatomic Pathology Division, San

Martino Hospital, Genoa, Italy

C. Palmiere $(\bowtie)$

University Centre of Legal Medicine, Rue du Bugnon 21,

1011 Lausanne, Switzerland

e-mail: cristian.palmiere@chuv.ch
Keywords Lactic acidosis · Metformin - Fatal intoxication · Renal function $\cdot$ Metformin-associated lactic acidosis

\section{Introduction}

Metformin is an oral antihyperglycemic agent used in the management of type 2 diabetes mellitus. The mechanisms of action are multifaceted and include decreased hepatic glucose production (primarily through the inhibition of gluconeogenesis, but also through glycogenolysis), increased insulin-stimulated glucose uptake in skeletal muscle and adipocytes, as well as a delayed glucose absorption rate from the gastrointestinal tract. An additional pharmacologic effect is increased intestinal lactate production. Metformin can be responsible for potentially lifethreatening metabolic acidosis with an increased blood lactate level. Although rare, this condition carries a high risk of mortality and may occur in therapeutic use as well as in acute overdose. Notwithstanding the complex pathogenesis, still not completely understood, metformin-induced lactic acidosis is postulated as being caused by enhanced lactate production in the intestines and gluconeogenesis inhibition in the liver. Both of these mechanisms would cause increased gluconeogenic substrate concentration such as pyruvate and alanine. This would thus be the key link between metformin and lactic acidosis [1-3].

Metformin overdose, both accidental and intentional, has been commonly reported, though fatal cases are infrequent. In the 2008 annual report of the American Association of Poison Control Centers (AAPCC), 6,538 cases of biguanide exposure were reported with 17 patients experiencing major adverse outcomes and 8 deaths. A 5 -year review of toxic exposures reported in poison control centers in the USA revealed that only 4,072 out of the nearly 11 million exposures involved metformin, with a total of 9 deaths $(0.2 \%$ of all metforminrelated exposures), 32 cases with life-threatening signs or symptoms and/or residual disability $(0.8 \%)$, and 187 cases with moderate clinical effects $(4.6 \%)$ [1-5]. 
Even though lactic acidosis is a rare complication relative to the very widespread use of the drug, its possible occurrence still influences treatment strategies in type 2 diabetes mellitus, particularly in patients with impaired renal function and in those with severely compromised oxygenation and tissue perfusion that may predispose to increased lactate production. Liver dysfunction, past history of lactic acidosis (of any cause), chronic respiratory failure, and alcohol abuse are classic contraindications to metformin use. Congestive heart failure has recently been removed from the list of diseases absolutely contraindicated with metformin administration, although a warning for concomitant use in this condition remains [6-8].

In this report, we describe an autopsy case involving a 70year-old woman suffering from diabetes mellitus, obesity, and impaired renal function who received metformin treatment. Toxicology revealed markedly increased blood metformin concentration, and biochemical investigations showed increased vitreous lactate and increased blood and vitreous $\beta$-hydroxybutyrate. The cause of death as well as the relationships pertaining to ante- and postmortem laboratory results, precipitating causes, and metabolic disturbances that likely led to or contributed to death are herein discussed.

\section{Case history}

An obese (weight $117 \mathrm{~kg}$, height $165 \mathrm{~cm}$ ) 70 -year-old woman suffering from hypertension, type 2 diabetes mellitus, and polyarthritis was admitted to the hospital due to fall-related injuries mainly consisting of right patella fracture. On admission, physical examination revealed a good general state and mild edema in the lower extremities, whereas laboratory analyses showed hyperglycemia, increased glycated hemoglobin level, impaired renal function, and anemia. During hospitalization (10 days), the patient received irbesartan, furosemide, insulin, heparin, and metformin (500 mg at 8 a.m., $1,000 \mathrm{mg}$ at 1 p.m., and 1,000 mg at 7 p.m.). The patient was subsequently transferred to a rehabilitation clinic. Physical examination performed on admission showed mild edema in the lower extremities as well as a distended abdomen. Cardiac function and hemodynamic status were relatively stable. The prescribed treatment consisted of heparin anticoagulation once daily, irbesartan $300 \mathrm{mg}$, furosemide $125 \mathrm{mg}$, insulin administered three or more times per day by injection, and metformin (500 $\mathrm{mg}$ at 8 a.m., $1,000 \mathrm{mg}$ at 1 p.m., and 1,000 $\mathrm{mg}$ at 7 p.m.). Insulin treatment was stopped 2 days after admission due to a lack of appetite and insufficient food intake. Three days after admission, blood glucose level was $230 \mathrm{mg} / \mathrm{ml}$ $(12.8 \mathrm{mmol} / \mathrm{l})$, and 5 units of insulin was administered. Four days after admission, the patient complained of severe itching and orticarioid-like reaction of the abdomen. An antihistaminic agent (cetirizine) was then added to the daily treatment. Five days after admission, neither insulin nor metformin was administered due to a worsening lack of appetite and insufficient food intake. Six days after admission, the patient had an episode of biliary vomit associated with chest, epigastric, and abdominal pain. Metformin was administered again at full dose $(2,500 \mathrm{mg})$. Physical examination revealed icteric sclera. The patient became agitated and was transferred to the intensive care unit of the local hospital. On admission, the patient lost consciousness, and cardiorespiratory arrest occurred. Cardiopulmonary resuscitation allowed only a partial hemodynamic recovery. Laboratory investigations showed lactic metabolic acidosis, hyperkalemia, and impaired renal function. Four hours postadmission, laboratory analyses showed no improvement. The patient died $8 \mathrm{~h}$ after admission despite resuscitation attempts. A medicolegal autopsy was ordered by the localinquiring authorities (public prosecutor) due to the unclear circumstances of death as well as possible correlations between medical malpractice and the fatal outcome.

\section{External examination, autopsy, and histology}

Height was $165 \mathrm{~cm}$ and weight $117 \mathrm{~kg}$ (BMI $40 \mathrm{~kg} / \mathrm{m}^{2}$ ). External examination revealed the presence of abdominal bruises and linear excoriations on the skin of different body parts, particularly the abdomen and left thigh. Edema of the face was also observed. Internal examination revealed rib fractures and intercostal space hemorrhagic infiltrations consistent with cardiopulmonary resuscitation marks. The heart weighted $450 \mathrm{~g}$. Heart examination revealed mild left ventricle hypertrophy. Examination of the pleural cavities showed bilateral effusion (approximately $100 \mathrm{ml}$ in each cavity). The lungs were relatively edematous and congested (right lung $650 \mathrm{~g}$, left lung $550 \mathrm{~g}$ ). On cut section, both edematous lungs showed subpleural emphysematous areas in both apexes with no evidence of any focal lesions. Pulmonary embolism was not observed. The spleen weighed $200 \mathrm{~g}$ and was moderately enlarged with a tense, smooth capsule and congested parenchyma. The cut section of the liver that weighed 2,100 $\mathrm{g}$ was congested and showed multiple yellow areas. No identifiable pill components or fragments were found in the stomach contents or upper gastrointestinal tract. The brain and the kidney were macroscopically unremarkable.

Histology confirmed the presence of left ventricular hypertrophy with no evidence of subendocardial hemorrhage or acute myocardial infarction. The lungs showed congestion and edema as well as areas of emphysema, atelectasis, and hemorrhage foci. Immunohistochemistry of the lungs using antitryptase antibodies was negative. Histology also revealed congestion and areas of fatty degeneration of the liver as well as diffuse mesangial sclerosis and nodular glomerulosclerosis (Kimmelstiel-Wilson lesion) of the kidneys. 


\section{Toxicology and biochemistry}

Peripheral blood from the femoral vein, cardiac blood, bile and vitreous humor, as well as samples of certain tissues were recovered for toxicological and biochemical analyses.

Toxicology included ethanol and other volatile compounds determination as well as general screening for nonvolatile drugs, poisons, and metabolites by gas chromatography-mass spectrometry (GC-MS) using commercial mass spectrum libraries, high-performance liquid chromatography with diode array detection (HPLC-DAD), and headspace-gas chromatography-flame ionization detection (HS-GC-FID) for volatile compound analysis.

Metformin analysis was performed utilizing a reverse-phase (RP) HPLC method. Phenformin (another biguanide derivative) was chosen as internal standard. The two compounds were separated in a C18 column by a mixture of acetonitrilemethanol-water (45:10:45\%) containing sodium dodecyl sulfate (NaDS) $0.01 \mathrm{M}$. The mobile phase was adjusted to $\mathrm{pH} 4.0$ with acetic acid. Diode array detector was employed for the quantitative analysis of the analytes. The metformin concentration in the blood was measured at $230 \mathrm{~nm}$. The blood sample was simply deproteinized by acetonitrile, diluted 1:5 with hydrochloric acid $0.01 \mathrm{M}$, and directly injected in the HPLC system. A five-point calibration curve was studied within the range of $5-100 \mathrm{mg} / \mathrm{l}$.

Acetone was determined during ethanol analysis in the blood by using HS-GC-FID. Toxicology failed to detect ethanol and revealed the presence of lidocaine (within therapeutic range), acetone (120 mg/l, corresponding to $12 \mathrm{mg} / \mathrm{dl}$ and 2 , $070 \mu \mathrm{mol} / \mathrm{l})$, and metformin $(47.3 \mu \mathrm{g} / \mathrm{ml})$ in the femoral blood collected during autopsy (therapeutic range $0.5-2.5 \mu \mathrm{g} / \mathrm{ml}$ ). Metformin concentration in the peripheral blood collected during hospitalization and prior to death was $42 \mu \mathrm{g} / \mathrm{ml}$.

Biochemical investigations were performed in the femoral blood and vitreous humor. Glycated hemoglobin was determined in the whole femoral blood. Glucose, sodium, chloride, and lactate were measured in vitreous. Betahydroxybutyrate was determined in the blood and vitreous.

Vitreous sodium, chloride, glucose, and lactate were determined by enzymatic assays on a Dimension ${ }^{\circledR}$ Xpand $^{\circledR}$ Plus Integrated Chemistry System (Siemens Healthcare Diagnostics, Inc., Deerfield, IL, USA). The concentrations of all substances were determined without diluting samples.

Glycated hemoglobin was determined on the whole femoral blood stored in tubes containing ethylenediaminetetraacetic acid (EDTA) by ion-exchange HPLC (Bio-Rad D-10 Dual Program, Hercules, CA, USA).

Beta-hydroxybutyrate concentrations were determined on Cobas Mira Plus (Roche Diagnostics, Switzerland) by an enzymatic photometric method adapted in house from the technique described by Ruell and Gass. Frozen femoral blood and vitreous humor samples were thawed overnight at $4{ }^{\circ} \mathrm{C}$ and deproteinized with perchloric acid. Supernatant was used for analysis.

Results of analyzed biological fluids and clinical reference values are summarized in Table 1. Based on the results of clinical data and postmortem investigations, the cause of death was determined to be terminal cardiocirculatory arrest resulting from lactic acidosis due to metformin intoxication.

\section{Discussion}

Lactic acidosis is the most frequent cause of metabolic acidosis and can result from an imbalance of lactic acid production and degradation. Cases of lactic acidosis are conventionally classified into type A (anaerobic) and type B (aerobic). Type A occurs in situations characterized by tissue hypoperfusion and hypoxia, whereas type B includes all other forms with no evidence of tissue hypoxia. It must be highlighted, however, that this distinction has become partly obsolete, since restricted oxygen supply and metabolic factors often act simultaneously $[6,9]$.

A serious adverse effect of metformin in certain individuals is type B lactic acidosis, also known as metformin-associated lactic acidosis (MALA). Metformin is a small molecule (molecular weight, 165.8 Da) that is primarily absorbed from the small intestine. Metformin absorption is incomplete, with $20-30 \%$ found in the feces. Oral bioavailability is $40-60 \%$, depending on the dose ingested, with greater doses producing lower bioavailability. Metformin is thought to have a plasma $t$ of 0.5 between 4 and $8.7 \mathrm{~h}$, minimal protein binding. The drug is mainly excreted unchanged by the kidney $(90 \%)$ with a clearance 3.7 to 5 times the creatinine clearance. The rate of absorption is slower than the rate of elimination, which makes absorption to be a late-limiting step in the elimination half-life $[10,11]$.

The pathophysiology of MALA is not completely understood and is thought to be due to a shift in the intracellular redox potential from aerobic to anaerobic metabolism and decreased lactate utilization by suppression of hepatic gluconeogenesis. The occurrence of MALA has been generally observed during therapeutic dosage rather than overdose. In patients with normal renal function, about $90 \%$ of the absorbed metformin is eliminated and unchanged by glomerular filtration and tubular secretion within the first $24 \mathrm{~h}$. Traditional theory suggests that MALA occurs in the context of comorbidities that may result in drug accumulation (such as impaired renal function), elevated circulating lactate levels, or both. The link between metformin administration and lactic acidosis has been called into question by some, suggesting that MALA has typically been observed in the setting of other illnesses that are more likely to be the cause of lactic acidosis rather than incriminating metformin itself. Some data showed that metformin accumulation in the blood does not necessarily lead 


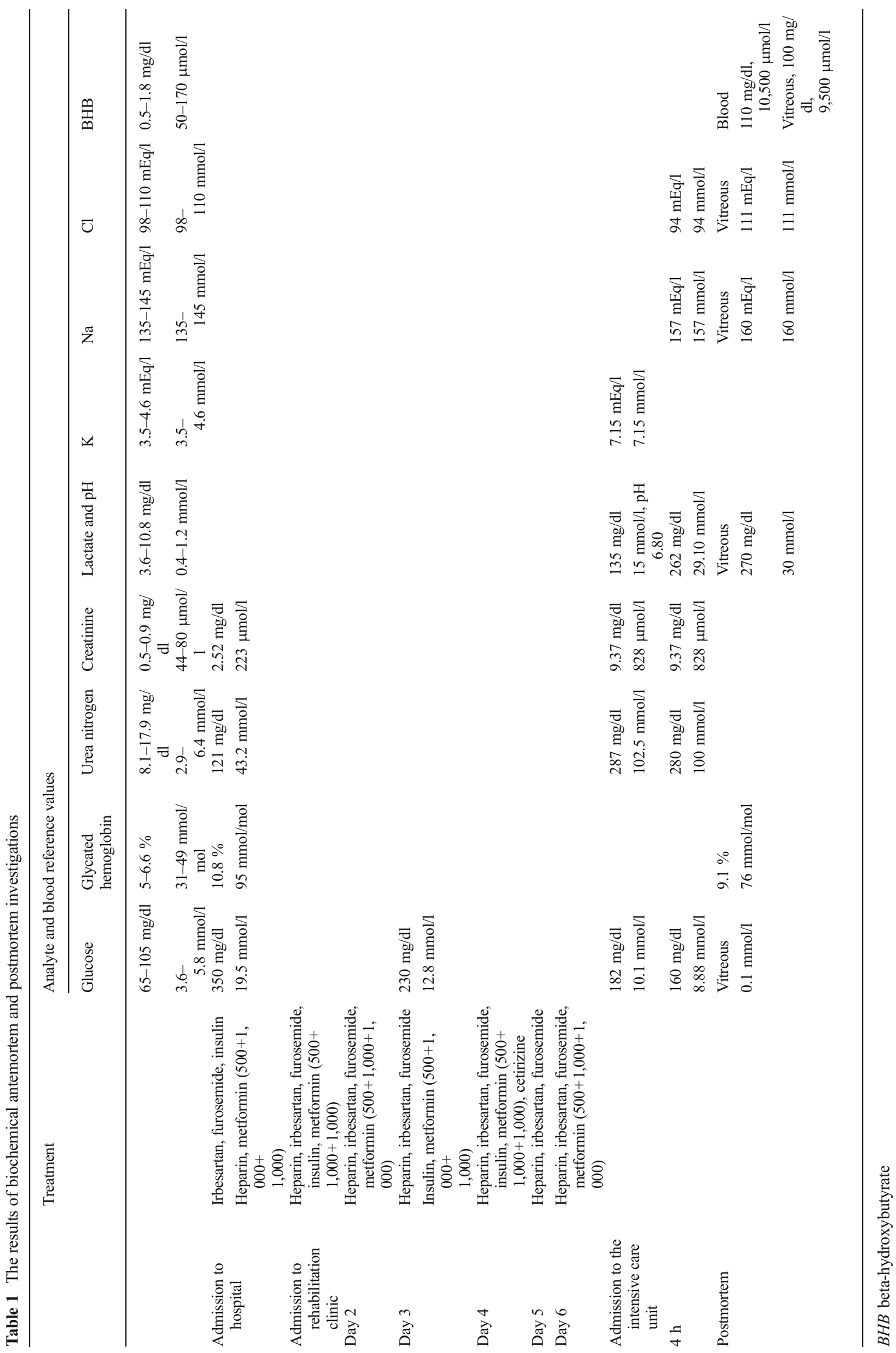


to lactic acidosis and failed to confirm the existence of a correlation between blood metformin levels and mortality, suggesting that the underlying causes of acidosis play a more important role than metformin administration itself on outcome. However, lactic acidosis during metformin treatment has been observed in patients with normal kidney function and without underlying conditions predisposing them to renal failure, hypoxia, and lactic acid accumulation [10-14].

There are only few data regarding MALA in the setting of acute metformin overdose, though several cases of severe lactic acidosis following acute metformin ingestion have been clinically documented. The annual report of the AAPCC regularly mentions fatal cases in which acute metformin ingestion is most probably or undoubtedly responsible for death. Though some authors have denied any causal involvement and postulated that lactic acidosis in acute overdose is primarily due to the hemodynamic instability and shock syndrome following drug ingestion rather than the metabolic effects of metformin itself, the conclusions of other studies have suggested that severe lactic acidosis may also occur after acute metformin monooverdose in the absence of comorbidities. Clinical data and retrospective observation are at present not suitable to decide upon this issue definitively [12-16].

Since MALA occurs infrequently with therapeutic use and fatal cases are extremely rare in clinical practice, only a few reports exist in the literature with both complete antemortem medical records and detailed postmortem investigation findings. In most cases, exhaustive clinical and postmortem analysis results are absent or partially available. In Table 2, we have summarized the main clinical and postmortem findings (where available) in fatal cases related to therapeutic use or suicidal ingestion that we have collected upon literature review and the annual reports of the AAPCC from 2009 to 2011. Other fatal cases following therapeutic administration or suicidal use are mentioned in case series reports, but with limited available clinical and postmortem information $[3,9,14,17-31]$.

Lactic acidosis from metformin overdose is clinically indistinguishable from other forms of lactic acidosis. However, since MALA is primarily caused by impaired lactate clearance by the liver and is not the direct result of tissue hypoxia, the degree of clinical severity in these patients is generally not as important as in patients with lactic acidosis from other causes. Symptoms are often unspecific. Severe acidosis often leads to significant vasodilatation (due to decreased catecholamine binding to their respective receptors) and depressed myocardial contractility. Both of these mechanisms are thought to contribute to hypotension and hypoperfusion in severely acidemic patients, in turn leading to oliguria, acute renal insufficiency, and multisystem organ failure [3, 10, 18, 32].

The label on metformin in the USA is explicit with respect to renal contraindications and suggests drug administration based on serum creatinine cut points. Clinical guidelines outside of the USA incorporate the glomerular filtration rate (GFR) for the determination of metformin safety. Despite the clear recognition that impaired renal function may be a risk factor for adverse events with metformin use, a significant divergence regarding optimal conditions of safety exists across the globe [33-36].

In the case herein described, the cause of death was determined to be terminal cardiocirculatory arrest resulting from lactic acidosis due to metformin intoxication. Lactic acidosis was diagnosed through clinical laboratory analyses (blood lactate $15 \mathrm{mmol} / \mathrm{l}$ and $\mathrm{pH} 6.80$ on admission to the intensive care unit and blood lactate $29.10 \mathrm{mmol} / \mathrm{l} 4 \mathrm{~h}$ postadmission). The role of metformin as the main contributing factor in the development of lactic acidosis was easily identified based on the high drug concentrations in both blood sample collected during hospitalization $(42 \mu \mathrm{g} / \mathrm{ml})$ and femoral blood obtained during autopsy $(47.3 \mu \mathrm{g} / \mathrm{ml})$. Metformin accumulation was caused by severely impaired renal function, thus confirming that prescription was absolutely contraindicated in this patient. Accordingly, the forensic investigations led to the accused clinicians (those of the hospital as well as those of the rehabilitation clinic) being considered guilty of manslaughter by the public prosecutor.

Based on the available data, metformin appears to be minimally susceptible to postmortem redistribution [17]. Blood levels ranging from 0.5 to $2.5 \mu \mathrm{g} / \mathrm{ml}$ are considered within the therapeutic range, whereas concentrations over $5 \mu \mathrm{g} / \mathrm{ml}$ are generally considered toxic [17-31]. Lethal concentrations cannot be precisely defined. Cantrell et al. [17] described the case of a 57-year-old-woman with an antemortem blood metformin concentration of $210 \mathrm{mg} / \mathrm{l}$ and emphasized that the highest reported antemortem metformin concentration in which the patient survived was $165 \mathrm{mg} / \mathrm{l}$, though other authors described antemortem metformin concentrations of up to $380 \mathrm{mg} / \mathrm{l}$. Dell'Aglio et al. [3] analyzed 22 cases of acute metformin overdose and observed that the mortality rate in patients with a peak serum metformin concentration of greater than $50 \mu \mathrm{g} / \mathrm{ml}$ was $38 \%$, with a median peak metformin level of $110 \mu \mathrm{g} / \mathrm{ml}$ in nonsurvivors.

In the presented case, vitreous glucose value lower than $0.1 \mathrm{mmol} / 1$ indicated the absence of hyperglycemia when the patient died. Interestingly, markedly increased $\beta$-hydroxybutyrate levels were found in the blood $(10,500 \mu \mathrm{mol} / \mathrm{l})$ and vitreous $(9,500 \mu \mathrm{mol} / \mathrm{l})$. Fasting was postulated as the cause of this ketoacidosis, which was plausible retrospectively in a patient who had insufficient food intake and prolonged emesis the days prior to death. Since ante- and postmortem laboratory investigations excluded concomitant hyperglycemia, alternative causes for this patient's hyperketonemia seemed unlikely. What is remarkable in the case herein described is that concomitant metformin accumulation prevented gluconeogenesis, thus aggravating ketogenesis and ketoacidosis caused by fasting. 

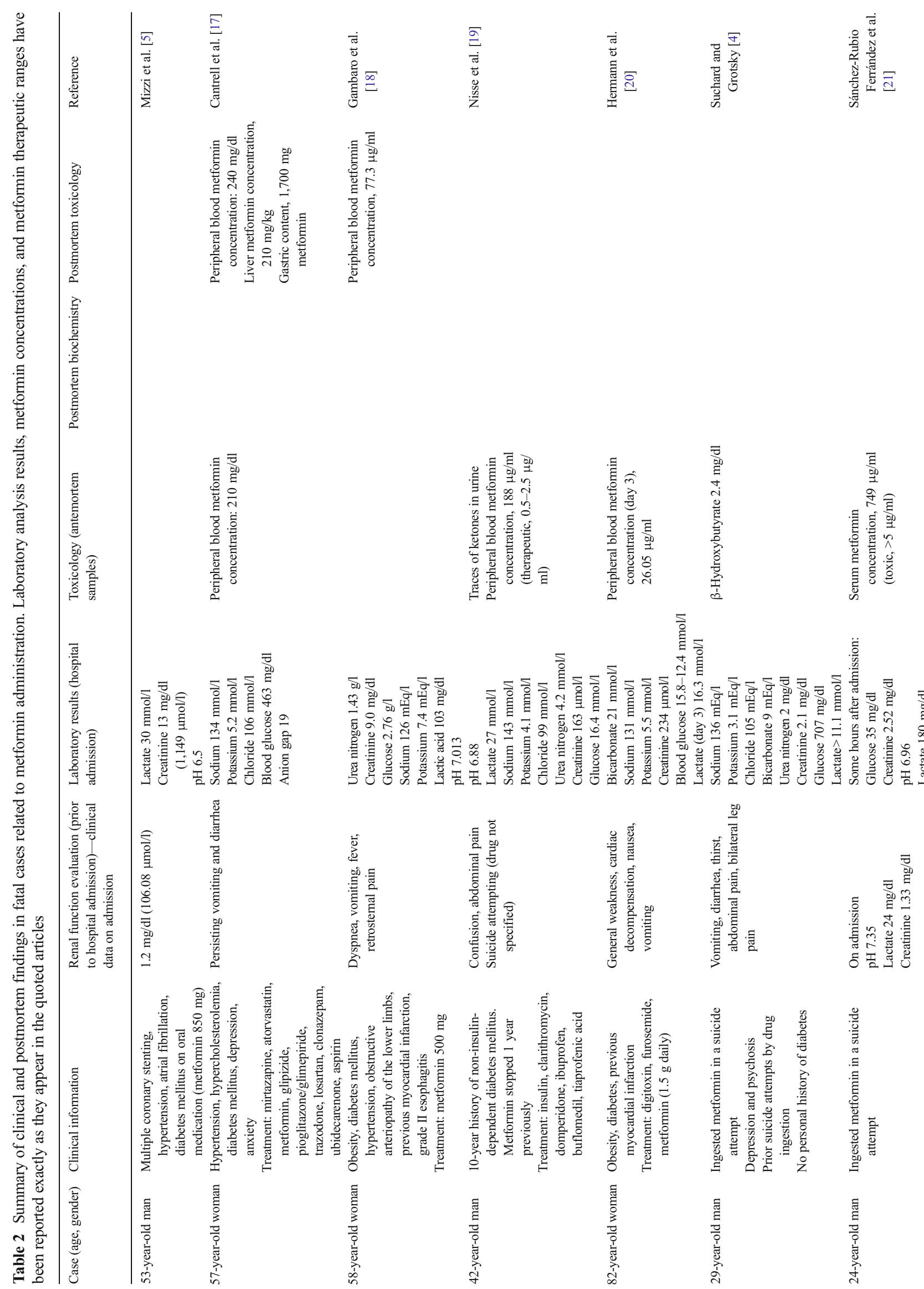


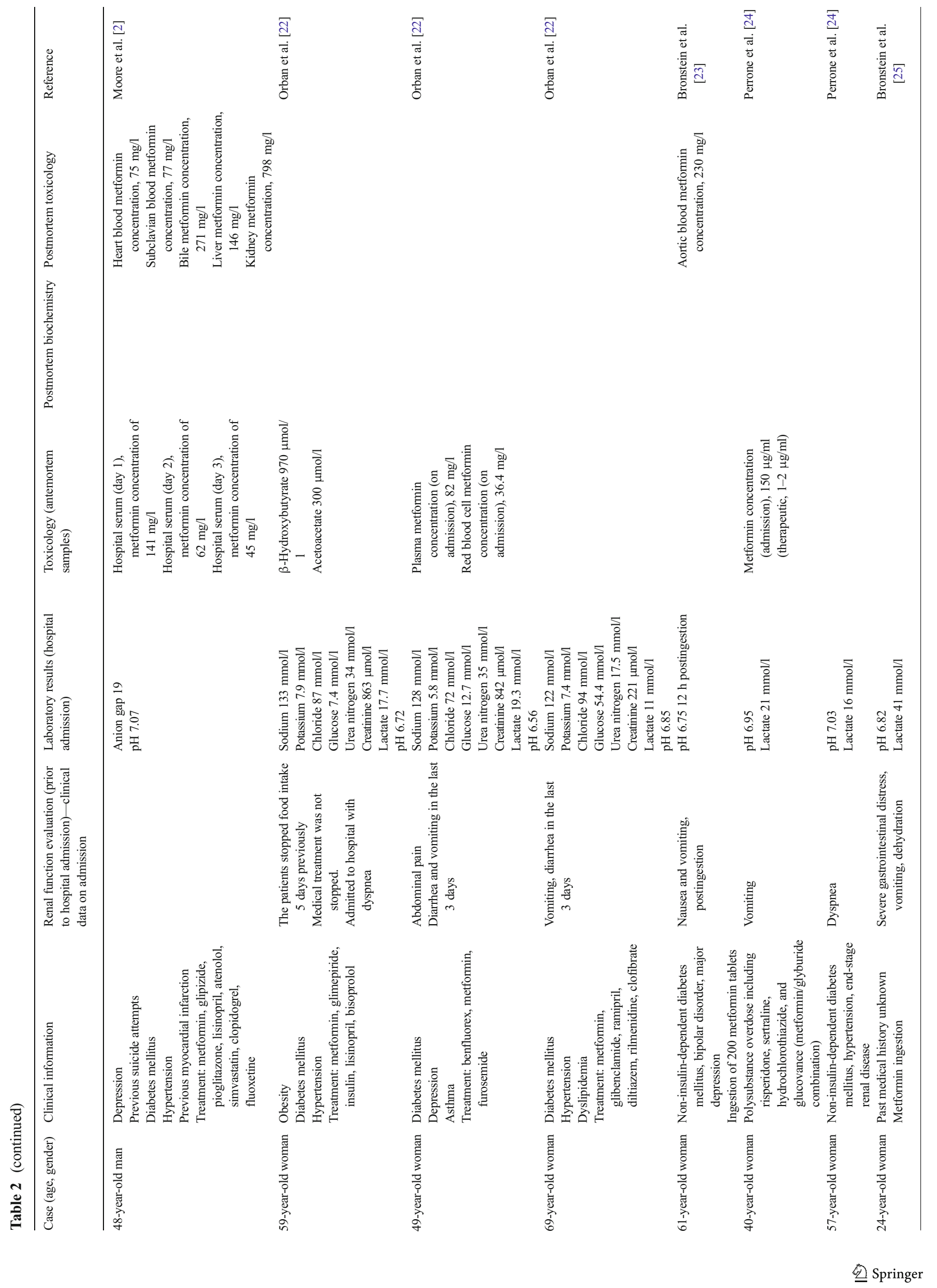




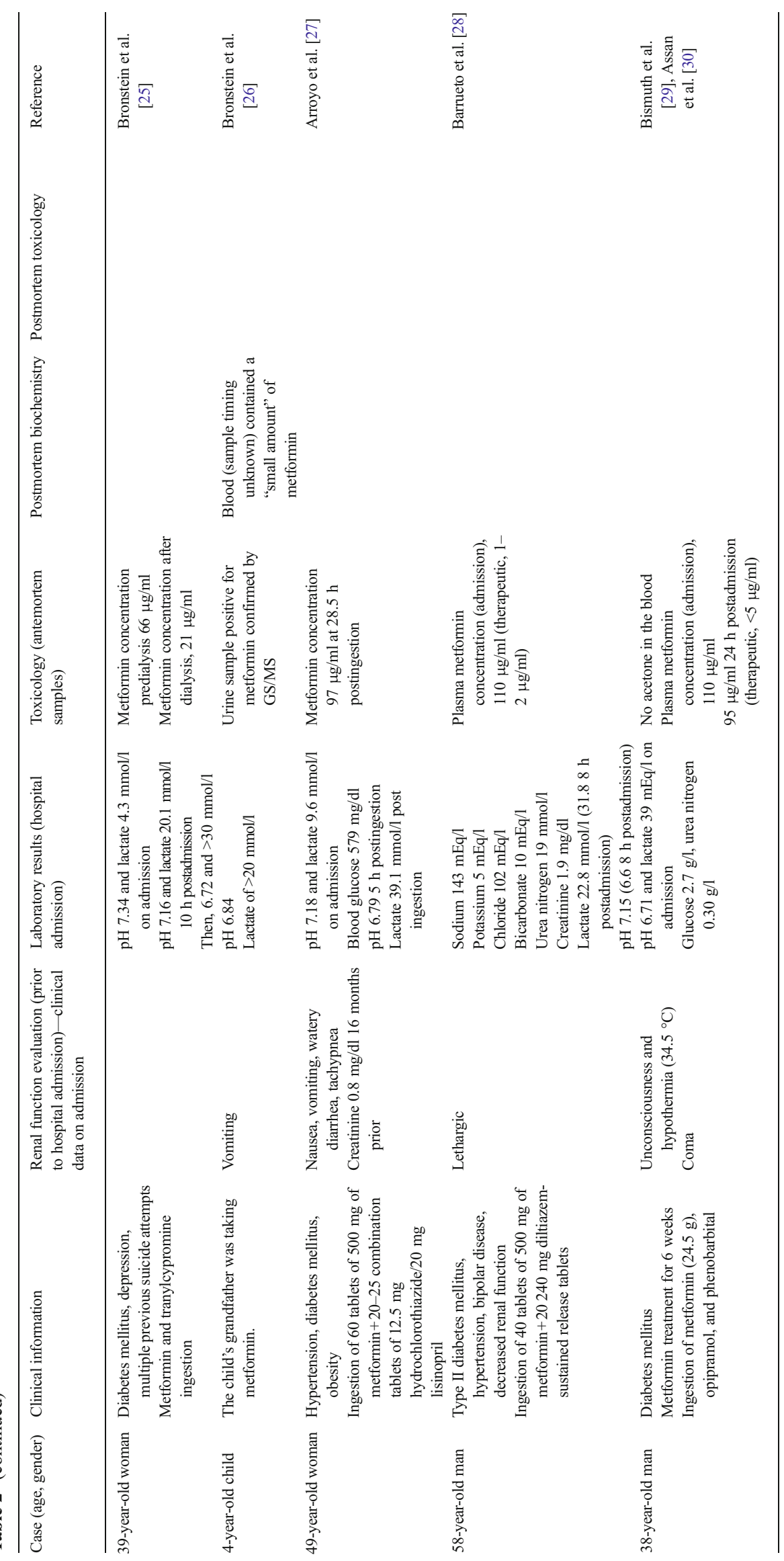


Lastly, it must be emphasized that severe lactic acidosis could be reliably identified only through antemortem biochemical investigations and that the increased vitreous lactate concentration revealed by postmortem biochemistry ( $270 \mathrm{mg} / \mathrm{dl}$, corresponding to $30 \mathrm{mmol} / \mathrm{l}$ ) would have not allowed antemortem lactic acidosis to be correctly diagnosed. Indeed, postmortem vitreous lactate levels of $30 \mathrm{mmol} / \mathrm{l}$ $270 \mathrm{mg} / \mathrm{dl}$ cannot be considered as a diagnostic evidence of antemortem lactic acidosis since values within this range are commonly found in vitreous after death. It has been shown that vitreous lactate levels rise with increasing postmortem time and that the postmortem vitreous lactate concentrations are due not only to the antemortem vitreous lactate levels and the postmortem metabolism of glucose, but other sources can also be responsible for lactate formation in vitreous and subsequent increased vitreous lactate concentrations after death. These observations confirm that the postmortem identification of lactic acidosis as the cause of death is a very difficult diagnosis in the absence of a suggestive context and that the correlation of medical history, autopsy observations, histology findings, and postmortem biochemical results is often decisive in identifying the cause of death, the precipitating conditions, and the predisposing disorders [37-39].

To conclude, though metformin is a highly effective, welltolerated, and generally safe antihyperglycemic agent in the treatment of type 2 diabetes, a significant risk of toxicity has been associated with its use in certain types of patients. The fatal case herein described is compatible with previous reports of metformin overdose and death in patients presenting risk factors that contributed to drug accumulation in blood and lactic acid generation. Since the potential toxicity of the drug is multifold, the determination of comorbidities and coingestants that may synergistically contribute to the toxic effects of metformin is of paramount importance in order to properly identify patients at particular risk for increased blood lactate levels.

Lastly, the presented case emphasizes the usefulness of performing exhaustive toxicology and postmortem biochemical analyses and correlating all potentially relevant investigations toward the more complete understanding of the pathophysiological mechanisms that may be involved in the death process.

Acknowledgments Authors are grateful to the anonymous reviewers, whose constructive and useful comments improved the quality of the article.

\section{References}

1. Al-Abri SA, Hayashi S, Thoren KL, Olson KR (2013) Metformin overdose-induced hypoglycemia in the absence of other antidiabetic drugs. Clin Toxicol (Phila) 51(5):444-447
2. Moore KA, Levine B, Titus JM, Fowler DR (2003) Analysis of metformin in antemortem serum and postmortem specimens by a novel HPLC method and application to an intoxication case. J Anal Toxicol 27(8):592-594

3. Dell'Aglio DM, Perino LJ, Kazzi Z, Abramson J, Schwartz MD, Morgan BW (2009) Acute metformin overdose: examining serum $\mathrm{pH}$, lactate level, and metformin concentrations in survivors versus nonsurvivors: a systematic review of the literature. Ann Emerg Med 54(6):818-823

4. Suchard JR, Grotsky TA (2008) Fatal metformin overdose presenting with progressive hyperglycemia. West J Emerg Med 9(3):160-164

5. Mizzi A, Landoni G, Corno L, Fichera M, Nuzzi M, Zangrillo A (2009) How to explain a $\mathrm{PaO}_{2}$ of $140 \mathrm{mmHg}$ in a venous line? Acta Biomed 80(3):262-264

6. Lalau JD (2010) Lactic acidosis induced by metformin: incidence, management and prevention. Drug Saf 33(9):727-740

7. Eurich DT, Majumdar SR, McAlister FA, Tsuyuki RT, Johnson JA (2008) Levels of evidence needed for changing indications, contraindications, and Food and Drug Administration labeling: the case of metformin. Arch Intern Med 171(11):1042-1043

8. Nye HJ, Herrington WG (2011) Metformin: the safest hypoglycaemic agent in chronic kidney disease? Nephron Clin Pract 118(4):c380-c383

9. Krzymień J, Karnafel W (2013) Lactic acidosis in patients with diabetes. Pol Arch Med Wewn 123(3):91-97

10. Spiller HA, Sawyer TS (2006) Toxicology of oral antidiabetic medications. Am J Health Syst Pharm 63(10):929-938

11. Mujtaba M, Geara AS, Madhrira M, Agarwala R, Anderson H, Cheng JT, Mohan S (2012) Toxicokinetics of metformin-associated lactic acidosis with continuous renal replacement therapy. Eur J Grud Metab Pharmacokinet 37(4):249-253

12. Wills BK, Bryant SM, Buckley P, Seo B (2010) Can acute overdose of metformin lead to lactic acidosis? Am J Emerg Med 28(8):857-861

13. Spiller HA, Quadrani DA (2004) Toxic effects from metformin exposure. Ann Pharmacother 38(5):776-780

14. Lalau JD, Mourlhon C, Bergeret A, Lacroix C (1998) Consequences of metformin intoxication. Diabetes Care 21(11):2036-2037

15. Duong JK, Furlong TJ, Roberts DM, Graham GG, Greenfield JR, Williams KM, Day RO (2013) The role of metformin in metforminassociated lactic acidosis (MALA): case series and formulation of a model of pathogenesis. Drug Saf. doi:10.1007/s40264-013-0038-6

16. Lacher M, Hermanns-Clausen M, Haeffner K, Brandis M, Pohl M (2005) Severe metformin intoxication with lactic acidosis in an adolescent. Eur J Pediatr 164(6):362-365

17. Cantrell LF, Nelson CL, Gary RD, McIntyre IM (2012) Fatal metformin intoxication with markedly elevated blood and liver concentrations. J Anal Toxicol 36(9):657-659

18. Gambaro V, Dell'acqua L, Farè F, Fidani M, Froldi R, Saligari E (2007) A case of fatal intoxication from metformin. J Forensic Sci 52(4):988-991

19. Nisse P, Mathieu-Nolf M, Deveaux M, Forceville X, Combes A (2003) A fatal case of metformin poisoning. J Toxicol Clin Toxicol 41(7):1035-1036

20. Hermann LS, Magnusson S, Möller B, Casey C, Tucker GT, Woods HF (1981) Lactic acidosis during metformin treatment in an elderly diabetic patient with impaired renal function. Acta Med Scand 209(6):519-520

21. Sánchez-Rubio Ferrández L, Martínez Iturriaga S, Hurtado Gómez MF, Apiñaniz Apiñaniz R (2013) Suicide to massive ingestion of metformin $(85 \mathrm{~g})$ : lactic acidosis followed by rhabdomyolysis with fatal heart damage. Farm Hosp 37(2):166-167

22. Orban JC, Giunti C, Levraut J, Grimaud D, Ichai C (2003) Metformin-associated lactic acidosis remains a serious complication of metformin therapy. Ann Fr Anesth Reanim 22(5):461-465

23. Bronstein AC, Spyker DA, Cantilena LR Jr, Rumack BH, Dart RC (2012) 2011 annual report of the American Association of Poison 
Control Centers' National Poison Data System (NPDS): 29th annual report. Clin Toxicol (Phila) 50(10):911-1164

24. Perrone J, Phillips C, Gaieski D (2011) Occult metformin toxicity in three patients with profound lactic acidosis. J Emerg Med 40(3):271-275

25. Bronstein AC, Spyker DA, Cantilena LR Jr, Green JL, Rumack BH, Dart RC (2011) 2010 annual report of the American Association of Poison Control Centers' National Poison Data System (NPDS): 28th annual report. Clin Toxicol (Phila) 49(10):910-941

26. Bronstein AC, Spyker DA, Cantilena LR Jr, Green JL, Rumack BH, Giffin SL (2010) 2009 annual report of the American Association of Poison Control Centers' National Poison Data System (NPDS): 27th annual report. Clin Toxicol (Phila) 48(10):979-1178

27. Arroyo AM, Walroth TA, Mowry JB, Kao LW (2010) The MALAdy of metformin poisoning: is CVVH the cure? Am J Ther 17(1):96-100

28. Barrueto F, Meggs WJ, Barchman MJ (2002) Clearance of metformin by hemofiltration in overdose. J Toxicol Clin Toxicol 40(2):177-180

29. Bismuth C, Gaultier M, Conso F, Assan R, Heuclin C (1976) Lactic acidosis induced by excessive ingestion of metformin. Eur $\mathrm{J}$ Toxicol Environ Hyg 9(1):55-57

30. Assan R, Heuclin C, Ganeval D, Bismuth C, George J, Girard JR (1977) Metformin-induced lactic acidosis in the presence of acute renal failure. Diabetologia 13(3):211-217

31. Ortega Carnicer J, Ambrós Checa A, Martín Rodríguez C, Ruiz Lorenzo F, Portilla Botelho M, Gómez Grande L (2007) Overdose of metformin secondary to acute renal insufficiency: a report of six cases. Med Intensiva 31(9):521-525
32. Dell'Aglio DM, Perino LJ, Todino JD, Algren DA, Morgan BW (2010) Metformin overdose with a resultant serum $\mathrm{pH}$ of 6.59 : survival without sequelae. J Emerg Med 39(1):e77-e80

33. Kosmalski M, Drozdowska A, Sliwinska A, Drzewoski J (2012) Inappropriate metformin prescribing in elderly type 2 diabetes mellitus (T2DM) patients. Adv Med Sci 57(1):6570

34. Tschöpe D, Hanefeld M, Meier JJ, Gitt AK, Halle M, Bramlage P, Schumm-Draeger PM (2013) The role of co-morbidity in the selection of antidiabetic pharmacotherapy in type-2 diabetes. Cardiovasc Diabetol 12:62

35. Lipska KJ, Bailey CJ, Inzucchi SE (2011) Use of metformin in the setting of mild-to-moderate renal insufficiency. Diabetes Care 34(6):1431-1437

36. Devetzis V, Passadakis P, Panagoutsos S, Theodoridis M, Thodis E, Georgoulidou A, Vargemezis V (2011) Metformin-related lactic acidosis in patients with acute kidney injury. Int Urol Nephrol 43(4):1243-1248

37. Boulagnon C, Garnotel R, Fornes P, Gillery P (2011) Postmortem biochemistry of vitreous humor and glucose metabolism: an update. Clin Chem Lab Med 49(8):1265-1270

38. Zilg B, Alkass K, Berg S, Druid H (2009) Postmortem identification of hyperglycemia. Forensic Sci Int 185(1-3):89-95

39. Palmiere C, Sporkert F, Vaucher P, Werner D, Bardy D, Rey F, Lardi C, Brunel C, Augsburger M, Mangin P (2012) Is the formula of Traub still up to date in antemortem blood glucose level estimation? Int J Legal Med 126(3):407-413 